Revue d'histoire de l'Amérique française

REYUE D.HISTOIRE DE L'AMÉRIQUE FRANÇAISE

Communauté urbaine de Montréal. Les Édifices scolaires. Répertoire d'architecture traditionnelle sur le territoire de la Communauté urbaine de Montréal, 1980. 319 p. \$5.00.

\title{
Robert Lahaise
}

Volume 35, numéro 3, décembre 1981

URI : https://id.erudit.org/iderudit/303997ar

DOI : https://doi.org/10.7202/303997ar

Aller au sommaire du numéro

Éditeur(s)

Institut d'histoire de l'Amérique française

ISSN

0035-2357 (imprimé)

1492-1383 (numérique)

Découvrir la revue

Citer ce compte rendu

Lahaise, R. (1981). Compte rendu de [Communauté urbaine de Montréal. Les Édifices scolaires. Répertoire d'architecture traditionnelle sur le territoire de la Communauté urbaine de Montréal, 1980. 319 p. \$5.00.] Revue d'histoire de

l'Amérique française, 35(3), 435-436. https://doi.org/10.7202/303997ar d'utilisation que vous pouvez consulter en ligne.

https://apropos.erudit.org/fr/usagers/politique-dutilisation/ 
COMMUNAUTÉ URBAINE DE MONTRÉAL. Les Édifices scolaires.

Répertoire d'architecture traditionnelle sur le territoire de la Communauté urbaine de Montréal, 1980. 319 p. $\$ 5.00$ 
La Communauté urbaine de Montréal délaissant provisoirement Stades et Expos, nous offre le premier d'une série de douze volumes qui seront consacrés à notre architecture traditionnelle, tant religieuse que militaire, civile, industrielle, commerciale, domestique et même rurale ou commémorative.

Le but est aussi simple que louable: c'est en étudiant nos édifices anciens que nous apprendrons à les apprécier, et à tenter alors de les recycler plutôt que de les démolir. La méthodologie utilisée est cependant moins claire: sans table des matières; certaines photos doublées sans raison; une introduction non signée, intéressante au point de vue de l'évolution architecturale, mais insuffisante pour nous expliciter la démarche ethno-historique qui sera poursuivie; de plus, l'actuel volume traite des Édifices scolaires. Or, un autre sera consacré aux Couvents. Sachant que chez les francophones, les deux s'identifiaient presque infailliblement durant la période choisie (qui va jusqu'en 1939, p. VIII), on constate qu'il y a évidemment ambiguïté dans cette division. C'est peut-être l'explication des 30 pages consacrées à l'Université McGill, 20 au Macdonald College - McGill, et 6 à l'Université de Montréal.

Il n'en demeure pas moins que cette série en sera une de base pour l'inventaire de notre architecture traditionnelle. Il est de plus encourageant de constater que, grâce à l'opinion publique, nos dirigeants songent maintenant à substituer à leurs récentes hécatombes une restauration humanisée de notre insécure Montréal. 